\title{
Inhibition of infarction-induced sympathetic innervation with endothelin receptor antagonism via a PI3K/GSK-3 $\beta$-dependent pathway
}

\author{
T-M Lee ${ }^{1,2,3}$, Nen-Chung Chang ${ }^{3,4}$ and Shinn-Zong Lin ${ }^{5}$
}

\begin{abstract}
Although endothelin (ET)-1 has been shown to upregulate nerve growth factor (NGF) expression, the molecular mechanisms are largely unknown. Phosphatidylinositol 3-kinase (PI3K)/Akt/glycogen synthase kinase (GSK)-3 $\beta$ signal has been implicated in the regulation of NGF. We investigated whether selective ET receptor blockers attenuated cardiac sympathetic reinnervation through restoring PI3K/Akt/GSK-3 $\beta$ activity. After ligation of the left anterior descending artery, male Wistar rats were randomized to either vehicle, atrasentan (an $\mathrm{ET}_{\mathrm{A}}$ receptor antagonist) or A-192621 (an $\mathrm{ET}_{\mathrm{B}}$ receptor antagonist) for 4 weeks. Sympathetic hyperinnervation after infarction was confirmed by myocardial norepinephrine measurement and immunofluorescent analysis. Post infarction was associated with increased reactive oxygen species (ROS), as measured by myocardial superoxide levels and dihydroethidine fluorescence staining. This was paralleled by a significant upregulation of NGF expression on mRNA and protein levels in the vehicle-treated rats, which reduced after administering atrasentan, not A-192621. Arrhythmic scores in the vehicle-treated rats were significantly higher than those treated with atrasentan. In an in vivo study atrasentan-induced decreased NGF was associated with activation of PI3K/Akt signaling pathway, which was further confirmed by the ex vivo study showing the restoration of NGF levels after coadministration of PI3K inhibitors (wortmannin and LY294002). Lithium chloride, an inhibitor of GSK-3 $\beta$, did not provide additional attenuated NGF levels compared with atrasentan alone. Finally, atrasentan-attenuated NGF levels were reversed in the presence of peroxynitrite generator. $\mathrm{ET}_{\mathrm{A}}$ receptor antagonism is a mediator to attenuate sympathetic hyperinnervation probably through restoration of PI3K/Akt/GSK-3 $\beta /$ ROS signaling pathway, a potential pharmacological target for arrhythmias after infarction.

Laboratory Investigation (2017) 97, 243-255; doi:10.1038/labinvest.2016.138; published online 19 December 2016
\end{abstract}

We have previously demonstrated that endothelin (ET) receptor antagonists attenuate arrhythmic susceptibility after infarction. ${ }^{1}$ The ET system is activated in various pathophysiological states including ventricular remodeling after myocardial infarction (MI). ${ }^{2}$ ET-1 exerts biological activities through stimulation of the $\mathrm{ET}_{\mathrm{A}}$ and $\mathrm{ET}_{\mathrm{B}}$ receptors. ${ }^{2}$ Immunoreactivity for $\mathrm{ET}_{\mathrm{A}}$ and $\mathrm{ET}_{\mathrm{B}}$ receptors was detected in myocardial sympathetic nerve varicosities. ${ }^{3} \mathrm{ET}_{\mathrm{A}}$ receptor antagonists have an antiarrhythmic effect in pathological hearts. ${ }^{4}$ Nerve spouting has been shown to be an important contributing factor for the occurrence of ventricular arrhythmias and sudden cardiac death in healing or healed stages of infarction in animals ${ }^{5,6}$ and humans. ${ }^{7}$ ET-1 has been shown to upregulate nerve growth factor $(N G F)$ mRNA and protein levels through an $\mathrm{ET}_{\mathrm{A}}$ receptor pathway during the development and regeneration of cardiac sympathetic innervation. ${ }^{1,8}$ However, the signaling pathways through which ET receptor antagonists attenuate sympathetic innervation through reduced NGF expression are not known.

Although previous studies have suggested that ET-1induced NGF augmentation was not mediated by phosphatidylinositol 3-kinase (PI3K), ${ }^{8}$ it remained controversial. The interaction of ET-1 with their receptors triggered a number of signaling cascades including PI3K. ${ }^{9}$ Glycogen synthase kinase (GSK)-3, a downstream effector of PI3K, is a multifaceted protein with diverse cellular and neurophysiological

'Department of Medicine, Cardiology Section, China Medical University-An Nan Hospital, Tainan, Taiwan; ${ }^{2}$ Department of Medicine, China Medical University, Taichung, Taiwan; ${ }^{3}$ Department of Internal Medicine, School of Medicine, College of Medicine, Taipei Medical University, Taipei, Taiwan; ${ }^{4}$ Division of Cardiology, Department of Internal Medicine, Taipei Medical University Hospital, Taipei, Taiwan and ${ }^{5}$ Department of Neurosurgery, Bioinnovation Center, Tzu Chi foundation, Buddhist Tzu Chi General Hospital, Tzu Chi University, Hualien, Taiwan

Correspondence: Professor T-M Lee, MD, Department of Medicine, Cardiology Section, China Medical University-An Nan Hospital, 66, Sec 2, Chang-Her Road, Tainan 709, Taiwan.

E-mail: tsungm.lee@msa.hinet.net

Received 7 May 2016; revised 17 November 2016; accepted 18 November 2016 
functions. GSK-3 $\beta$ is crucial to the regulation of axon morphogenesis in peripheral nervous system. ${ }^{10}$ Very recently, we have shown that pharmacological activation of the PI3K/ Akt/GSK-3 $\beta$ pathway led to increases in Nrf2 and HO-1, efficiently protecting cells from reactive oxygen species (ROS) stress during ventricular remodeling. ${ }^{11}$ The NGF promoter contains activator protein- $1,{ }^{12}$ which is subjected to redox regulation through its conserved cysteine residue. ${ }^{13}$ Previous studies have shown that peroxynitrite, the byproduct of $\bullet \mathrm{NO}$ and superoxide $\left(\mathrm{O}_{2}{ }^{-}\right)$, is an important trigger of NGF formation. ${ }^{14}$ A brief exposure to peroxynitrite induces NGF expression and secretion in astrocytes. ${ }^{14}$ We hypothesized that $\mathrm{ET}_{\mathrm{A}}$ receptor antagonists inhibited NGF expression via regulation of the PI3K/Akt/GSK-3 $\beta /$ ROS pathway. Thus, we assessed (1) whether chronic administration of selective $\mathrm{ET}_{\mathrm{A}}$ or $\mathrm{ET}_{\mathrm{B}}$ receptor antagonists can result in attenuated heart reinnervation after infarction and (2) whether PI3K/Akt/ GSK-3 $\beta /$ ROS axis involves the ET receptor antagonistsmediated NGF expression using the inhibitors of PI3K and GSK-3 $\beta$ and a peroxynitrite generator (3-morpholinosydnonimine, SIN-1).

\section{MATERIALS AND METHODS Animals}

This study was carried out in strict accordance with the recommendations in the Guide for the Care and Use of Laboratory Animals of the National Institutes of Health (NIH Publication No. 85-23, revised 1996). The protocol was approved by the Committee on the Ethics of Animal Experiments of the China Medical University (Permit Number: 103-48-N). All surgery was performed under ketamine-xylazine anesthesia, and all efforts were made to minimize suffering. Rats were kept under a $12 \mathrm{~h}$ light-dark cycle at a temperature of $23-27^{\circ} \mathrm{C}$ with water and chow ad libitum.

\section{Experiment 1 (ex vivo study)}

After anesthesia with ketamine-xylazine $(90-9 \mathrm{mg} / \mathrm{kg}$, intraperitoneally), male Wistar rats (250-300 g) were intubated and the anterior descending artery was ligated using a 6-0 silk as our previous description. ${ }^{15}$ Twenty hours after ligation, rats were randomly assigned into three groups so as to have approximately the same number of survivors in each group (Table 1): (1) vehicle group (saline); (2) atrasentan (5 mg/kg per day, a selective $\mathrm{ET}_{\mathrm{A}}$ receptor antagonist; Abbott Park, IL), or (3) A-192621 (30 mg/kg per day, a selective $\mathrm{ET}_{\mathrm{B}}$ receptor antagonist; Abbott Park, IL). These doses of atrasentan and A-192621 have been shown to be effective in blocking the $\mathrm{ET}_{\mathrm{A}}$ and $\mathrm{ET}_{\mathrm{B}}$ receptor in vivo, respectively. ${ }^{16}$ Sham rats underwent the same surgical procedures except for ligation.

The drugs were started $24 \mathrm{~h}$ after infarction, as drugs can exert maximum benefits at this timing window. ${ }^{17}$ The study duration was designed to be 4 weeks because the majority of the myocardial remodeling process in the rat $(70-80 \%)$ is complete within 3 weeks. ${ }^{18}$ The drugs were administered by
Table 1 Cardiac morphology, hemodynamics, and tissue NE concentration at the end of study

\begin{tabular}{|c|c|c|c|c|}
\hline & Sham & Infarction & & \\
\hline Parameters & Vehicle & Vehicle & Atrasentan & A-192621 \\
\hline No. of rats & 10 & 11 & 11 & 12 \\
\hline Body weight, g & $355 \pm 5$ & $357 \pm 7$ & $360 \pm 5$ & $362 \pm 7$ \\
\hline Heart rate, bpm & $405 \pm 8$ & $412 \pm 5$ & $407 \pm 5$ & $415 \pm 6$ \\
\hline LVESP, mm Hg & $105 \pm 2$ & $95 \pm 2^{*}$ & $88 \pm 2^{*, * *}$ & $102 \pm 2^{* * *}$ \\
\hline LVEDP, mm Hg & $5 \pm 1$ & $16 \pm 1^{*}$ & $11 \pm 2^{* * * *}$ & $18 \pm 2^{*}$ \\
\hline$+\mathrm{dP} / \mathrm{d} t, \mathrm{~mm} \mathrm{Hg} / \mathrm{s}$ & $7823 \pm 118$ & $3078 \pm 112^{*}$ & $4019 \pm 105^{*, * *}$ & $2981 \pm 96^{*}$ \\
\hline$-\mathrm{dP} / \mathrm{d} t, \mathrm{~mm} \mathrm{Hg} / \mathrm{s}$ & $5671 \pm 109$ & $2263 \pm 118^{*}$ & $3582 \pm 123^{* * * *}$ & $2563 \pm 103^{*}$ \\
\hline Infarct size, $\%$ of LV & - & $40 \pm 1$ & $40 \pm 1$ & $41 \pm 1$ \\
\hline LWW/BW, mg/g & $2.08 \pm 0.05$ & $3.05 \pm 0.10^{*}$ & $2.96 \pm 0.11^{*}$ & $3.12 \pm 0.11^{*}$ \\
\hline RVW/BW, mg/g & $0.53 \pm 0.04$ & $0.79 \pm 0.05^{*}$ & $0.64 \pm 0.05^{* *}$ & $0.75 \pm 0.03^{*}$ \\
\hline LungW/BW, mg/g & $4.01 \pm 0.12$ & $5.89 \pm 0.12^{*}$ & $4.58 \pm 0.08^{* * * *}$ & $5.59 \pm 0.12^{*}$ \\
\hline $\mathrm{LV} N \mathrm{NE} \mu \mathrm{g} / \mathrm{g}$ protein & $1.15 \pm 0.05$ & $2.37 \pm 0.12^{*}$ & $1.89 \pm 0.12^{* * * *}$ & $2.73 \pm 0.14^{*}$ \\
\hline
\end{tabular}

Abbreviations: BW, body weight; LungW, lung weight; LV, left ventricular; LVEDP, left ventricular end-diastolic pressure; LVESP, left ventricular endsystolic pressure; LVW, left ventricular weight; NE, norepinephrine; RVW, right ventricular weight.

${ }^{*} P<0.05$ compared with the sham; ${ }^{*} P<0.05$ compared with infarcted groups treated with vehicle and A-192621; ${ }^{* * * P}<0.05$ compared with the infarcted group treated with vehicle.

Values are mean \pm s.e.

daily oral gavage. In each treated group, drugs were withdrawn about $24 \mathrm{~h}$ before the end of the experiments in order to eliminate their pharmacological actions.

\section{Experiment 2 (ex vivo study)}

To assess the role of the PI3K/Akt pathway in $\mathrm{ET}_{\mathrm{A}}$ receptor antagonist-induced NGF suppression, infarcted rat hearts were treated with the PI3K specific inhibitors, wortmannin, or LY294002 infused with atrasentan. To further investigate the downstream signaling of PI3K/Akt, we assessed the involvement of the GSK-3 $\beta$ infused with lithium chloride ( $\mathrm{LiCl})$, a well-known inhibitor of GSK-3 activity. Four weeks after induction of MI by coronary ligation, infarcted rat hearts were isolated and subjected to vehicle $(\mathrm{NaCl})$, atrasentan $(3 \mu \mathrm{M})$, atrasentan+wortmannin $(100 \mathrm{nM}$, a PI3K inhibitor, Sigma-Aldrich ), atrasentan+LY294002 $(5 \mu \mathrm{M}$, another PI3K inhibitor, Calbiochem), $\mathrm{LiCl}(3 \mathrm{mM})$, or atrasentan+LiCl. Each heart was perfused with a non-circulating modified Tyrode's solution containing (in mM): $\mathrm{NaCl} 117.0, \mathrm{NaHCO}_{3}$ 23.0, $\mathrm{KCl}$ 4.6, $\mathrm{NaH}_{2} \mathrm{PO}_{4} 0.8, \mathrm{MgCl}_{2}$ 1.0, $\mathrm{CaCl}_{2} 2.0$, and glucose 5.5 , equilibrated at $37^{\circ} \mathrm{C}$ and oxygenated with a $95 \%$ $\mathrm{O}_{2}$ to $5 \% \mathrm{CO}_{2}$ gas mixture. The drugs were perfused for $30 \mathrm{~min}$. The doses of atrasentan, ${ }^{19}$ wortmannin, ${ }^{20}$ LY294002, ${ }^{20}$ and $\mathrm{LiCl}^{21}$ used in this study have been used as described previously. At the end of the study, all hearts 
( $n=5$ each group) were used for myocardial peroxynitrite measurement and for western blot for Akt, GSK-3 $\beta$, and NGF in the remote zone ( $>2 \mathrm{~mm}$ outside the infarct).

\section{Experiment 3 (ex vivo)}

To further confirm the mechanism by which $\mathrm{ET}_{\mathrm{A}}$ receptor antagonist acted as antioxidants, a peroxynitrite generator (SIN-1) was used in an ex vivo model. Four weeks after induction of MI by coronary ligation, infarcted rat hearts were isolated and subjected to vehicle $(\mathrm{NaCl})$, atrasentan $(3 \mu \mathrm{M})$, and atrasentan + SIN-1 $(37 \mu \mathrm{M})$. The dose of SIN-1 has been shown to be effective in modulating biological activities. ${ }^{22}$ In order to preclude non-specific actions to SIN-1, the relatively low concentration of SIN-1 was used. The heart was perfused as Experiment 2. At the end of the study, all hearts ( $n=5$ each group) were used for myocardial peroxynitrite measurement and western analysis for NGF protein in the remote zone.

\section{Hemodynamics and Infarct Size Measurements}

Hemodynamic parameters were measured in anesthetized rats with ketamine-xylazine $(90-9 \mathrm{mg} / \mathrm{kg}$, intraperitoneally) at the end of the study. A polyethylene Millar catheter was inserted into the right carotid artery and connected to a transducer (Model SPR-407, Miller Instruments, Houston, TX, USA) to measure left ventricular (LV) systolic and diastolic pressure as the mean of measurements of five consecutive pressure cycles as previously described. ${ }^{15}$ The maximal rate of LV pressure rise $(+\mathrm{dP} / \mathrm{d} t)$ and decrease $(-\mathrm{dP} / \mathrm{d} t)$ was measured. After the arterial pressure measurement, the heart was rapidly excised and suspended for retrograde perfusion with a Langendorff apparatus for the electrophysiological tests. At completion of the electrophysiological tests, the atria and the right ventricle were trimmed off, and the LV was rinsed in cold physiological saline, weighed, and immediately frozen in liquid nitrogen after obtaining a coronal section of the LV for infarct size estimation. A section, taken from the equator of the LV, was fixed in 10\% formalin and embedded in paraffin for determination of infarct size. Each section was stained with hematoxylin and eosin, and trichrome. The infarct size was determined as described previously. ${ }^{15}$ With respect to clinical importance, only rats with large infarction $(>30 \%)$ were selected for analysis.

\section{Ex Vivo Electrophysiological Studies}

To assess the potential arrhythmogenic risk of sympathetic innervation, we performed programmed electrical stimulation. After completing the perfusion of isolated hearts with a modified Tyrode's solution, the hearts were observed for 20 min to allow stabilization of contraction and rhythm. Because the residual neural integrity at the infarcted site is one of the determinants of the response to electrical induction of ventricular arrhythmias, ${ }^{23}$ only rats were included with the infarcted area of the LV totally replaced by scar tissue. Programmed electrical stimulation was performed through electrodes sewn on the epicardial surface of the right ventricular outflow tract. Induced arrhythmias were effected using an electrical Bloom stimulator. To induce ventricular arrhythmias, eight paced beats at a cycle length of $120 \mathrm{~ms}\left(\mathrm{~S}_{1}\right)$ were applied, followed by one to three extrastimuli $\left(S_{2}, S_{3}\right.$, and $S_{4}$ ) at shorter coupling intervals. The end point of ventricular pacing was induction of ventricular tachyarrhythmia. Ventricular tachyarrhythmias including ventricular tachycardia and ventricular fibrillation were considered non-sustained when it lasted $\leq 15$ beats and sustained when it lasted $>15$ beats. An arrhythmia scoring system was modified as previously described. ${ }^{24}$ When multiple forms of arrhythmias occurred in one heart, the highest score was used. The experimental protocols were typically completed within $10 \mathrm{~min}$. Pilot studies revealed no significant tissue edema during the time period required to complete these experiments.

\section{Real-Time RT-PCR of NGF}

Real-time quantitative reverse transcription-PCR (RT-PCR) was performed from samples obtained from the remote zone with the TaqMan system (Prism 7700 Sequence Detection System, PE Biosystems) as previously described. ${ }^{1}$ For NGF, the primers were $5^{\prime}$-CACACTGAGGTGCATAGCGT- $3^{\prime}$ (sense) and 5'-TGATGACCGCTTGCTCCTGT-3' (antisense). Co-amplification of glyceraldehyde-3-phosphate-dehydrogenase $(G A P D H)$ was used as an internal control. For $G A P D H$, the primers were 5'-CTTCACCACCATGGAGAA GGC-3' (sense) and 5'-GGCATGGACTGTGGTCATGAG-3' (antisense). Standard curves were plotted with the threshold cycles $v s$ log template quantities. For quantification, NGF expression was normalized to the expressed housekeeping gene GAPDH. Reaction conditions for 40 cycles of the amplification step were carried out.

\section{Western Blot Analysis of tyr688-Phosphorylated PI3K, PI3K, Akt2, ser9-Phosphorylated GSK-3 $\beta$, GSK-3 $\beta$, and NGF}

Samples obtained from the remote zone were homogenized with a kinematic polytron blender in $100 \mathrm{mM}$ Tris $\mathrm{HCl}, \mathrm{pH}$ 7.4, supplemented with $20 \mathrm{mmol} / \mathrm{l} \mathrm{EDTA}, 1 \mathrm{mg} / \mathrm{ml}$ pepstatin A, $1 \mathrm{mg} / \mathrm{ml}$ antipain, and $1 \mathrm{mmol} / \mathrm{l}$ benzamidin. Homogenates were centrifuged at $10000 \mathrm{~g}$ for $30 \mathrm{~min}$ to pellet the particulate fractions. The supernatant protein concentration was determined with the BCA protein assay reagent kit (Pierce). About $20 \mu \mathrm{g}$ of protein was separated by $10 \%$ SDSPAGE and electrotransferred onto a nitrocellulose membrane. Then, the nitrocellulose membrane was incubated with antibodies for $2 \mathrm{~h}$. Antigen-antibody complexes were detected with HRT substrate peroxide solution (Millipore Corporation, Billerica, MA, USA). Films were volume-integrated within the linear range of the exposure using a scanning densitometer. Relative abundance was obtained by normalizing the density of target proteins against that of $\beta$-actin. Experiments were replicated three times and results expressed as the mean value. 
Three isoforms of Akt exist, but only Akt1 and Akt2 are highly expressed in the heart. Very recently, Akt2 has been shown to have an important role in axon establishment and elongation through the regulation of GSK-3. ${ }^{25}$ Thus, Akt2 (Santa Cruz Biotechnology, Santa Cruz, CA, USA; catalog no. sc-5270) was used for evaluating active Akt2 levels. The Akt2 antibody specificity has been assessed as described previously. ${ }^{26}$ Phosphorylation of PI3K p85 SH2 domain at tyrosine 688 residue is associated with the activation of PI3K. ${ }^{27}$

The primary antibodies used were as follows: phosphorylated PI3K p85 (tyr688) (Upstate Biotechnology, Lake Placid, NY, USA), PI3K p85 (Upstate Biotechnology), Akt2 (Santa Cruz Biotechnology, catalog no. sc-5270), phosphorylated GSK-3 $\beta$ (ser9, Cell Signaling technology, Beverly, MA, USA), GSK-3 $\beta$ (BD Transduction Lab, San Diego, CA, USA), NGF (Chemicon, CA, USA), and $\beta$-actin (Santa Cruz Biotechnology).

\section{Immunofluorescent Studies of Tyrosine Hydroxylase, Growth-Associated Protein 43, and Neurofilament}

In order to investigate the spatial distribution and quantification of sympathetic nerve fibers, analysis of immunohistochemical staining for tyrosine hydroxylase (a selective axon marker), growth-associated protein 43 (GAP43) (a marker peptide for neuronal regeneration and outgrowth) and neurofilament (a dominant protein of the axonal cytoskeleton $^{28}$ ) was performed on LV muscle from the remote regions. Papillary muscles were excluded from the study because a variable sympathetic innervation has been reported. ${ }^{29}$ Paraffin-embedded sections were cut at a thickness of $5 \mu \mathrm{M}$. Tissues were incubated with anti-tyrosine hydroxylase (1:200; Chemicon), anti-GAP43 (1:400; Chemicon), and anti-neurofilament (1:1000; Chemicon) antibodies in $0.5 \%$ BSA in PBS overnight at $37^{\circ} \mathrm{C}$. The second antibody was monoclonal goat anti-mouse IgG conjugated to fluorescein isothiocyanate for tyrosine hydroxylase and rhodamine for GAP43 and neurofilament. Isotype-identical directly conjugated antibodies served as a negative control.

The density of nerve fibers was qualitatively estimated from 10 randomly selected fields at a magnification of $\times 400$. The nerve density was measured on the tracings by computerized planimetry (Image Pro Plus, CA, USA) as described previously. ${ }^{30}$ The value was expressed as the ratio of nerve fiber area to total area. The slides were coded so that the investigator was blinded to the rat identification.

\section{In Situ Detection of Superoxide}

For evaluating myocardial intracellular superoxide production using in situ dihydroethidium (DHE, Invitrogen Molecular Probes, Eugene, OR, USA) fluorescence, OCTembedded tissues were sectioned $(10 \mu \mathrm{m})$ at $-20^{\circ} \mathrm{C}$. After fixing, tissues were incubated with DHE in PBS $(10 \mu \mathrm{M})$ in a dark, humidified container at room temperature for $30 \mathrm{~min}$. Generation of superoxide radicals by tissue was demonstrated by a red fluorescence, which was detected through a $580-\mathrm{nm}$ long pass filter, using a digital camera mounted on an Olympus fluorescent microscope. The density of the images was reported as arbitrary units per millimeter square field.

\section{Laboratory Measurements}

Although cardiac innervation was detected by immunofluorescent staining of tyrosine hydroxylase, GAP43, and neurofilament, it did not imply that the nerves are functional. Thus, to examine the sympathetic nerve function, we measured LV norepinephrine levels from the remote zone. Total norepinephrine was measured using a commercial ELISA kit (Noradrenalin ELISA, IBL Immuno-Biological Laboratories, Hamburg, Germany). To estimate myocardial peroxynitrite formation, we measured free nitrotyrosine (as a marker for peroxynitrite formation) by ELISA (Cayman Chemical, Ann Arbor, MI, USA) in myocardial homogenates.

Superoxide production by myocardium from the remote zone was measured using lucigenin $(5 \mu \mathrm{M}$ bis- $\mathrm{N}-$ methylacridinium nitrate, Sigma, St. Louis, MO, USA)enhanced chemiluminescence as described previously. ${ }^{30}$ The specific chemiluminescence signal was calculated after subtraction of background activity and expressed as counts per minute per milligram weight $(\mathrm{cpm} / \mathrm{mg})$.

\section{Statistical Analysis}

Results are presented as mean \pm s.e. Statistical analysis was performed using the SPSS statistical package (SPSS, version 18.0, Chicago, IL, USA). Differences among the groups of rats were tested by an ANOVA. Subsequent analysis for significant differences between the two groups was performed with a multiple comparison test (Scheffe's method). Electrophysiological data (scoring of programmed electrical stimulationinduced arrhythmias) were compared by a Kruskal-Wallis test followed by a Mann-Whitney test. The significant level was assumed at a value of $P<0.05$.

\section{RESULTS}

\section{$\mathrm{ET}_{\mathrm{A}}$ Receptor Inhibition Improved Ventricular Remodeling}

We found no significant differences in mortality among the infarcted groups throughout the study. Either $\mathrm{ET}_{\mathrm{A}}$ or $\mathrm{ET}_{\mathrm{B}}$ blockade had little effect on gross cardiac morphology in the sham-operated rats (data not shown). Four weeks after infarction, the infarcted area of the LV was very thin and was totally replaced by fully differentiated scar tissue. After 4 weeks of treatment in infarcted rats, $\mathrm{ET}_{\mathrm{A}}$ blockade decreased systolic blood pressure significantly compared with vehicle and A-1921621 (Table 1). $\mathrm{ET}_{\mathrm{B}}$ blockade significantly increased systolic blood pressure compared with vehicle. The weight of the LV inclusive of the septum remained essentially constant 4 weeks after coronary artery occlusion among the infarcted groups. $+\mathrm{dP} / \mathrm{d} t,-\mathrm{dP} / \mathrm{d} t$, right ventricular weight/ body weight ratio, and lung weight/ body weight ratio were significantly improved in the atrasentan-treated infarcted group compared 

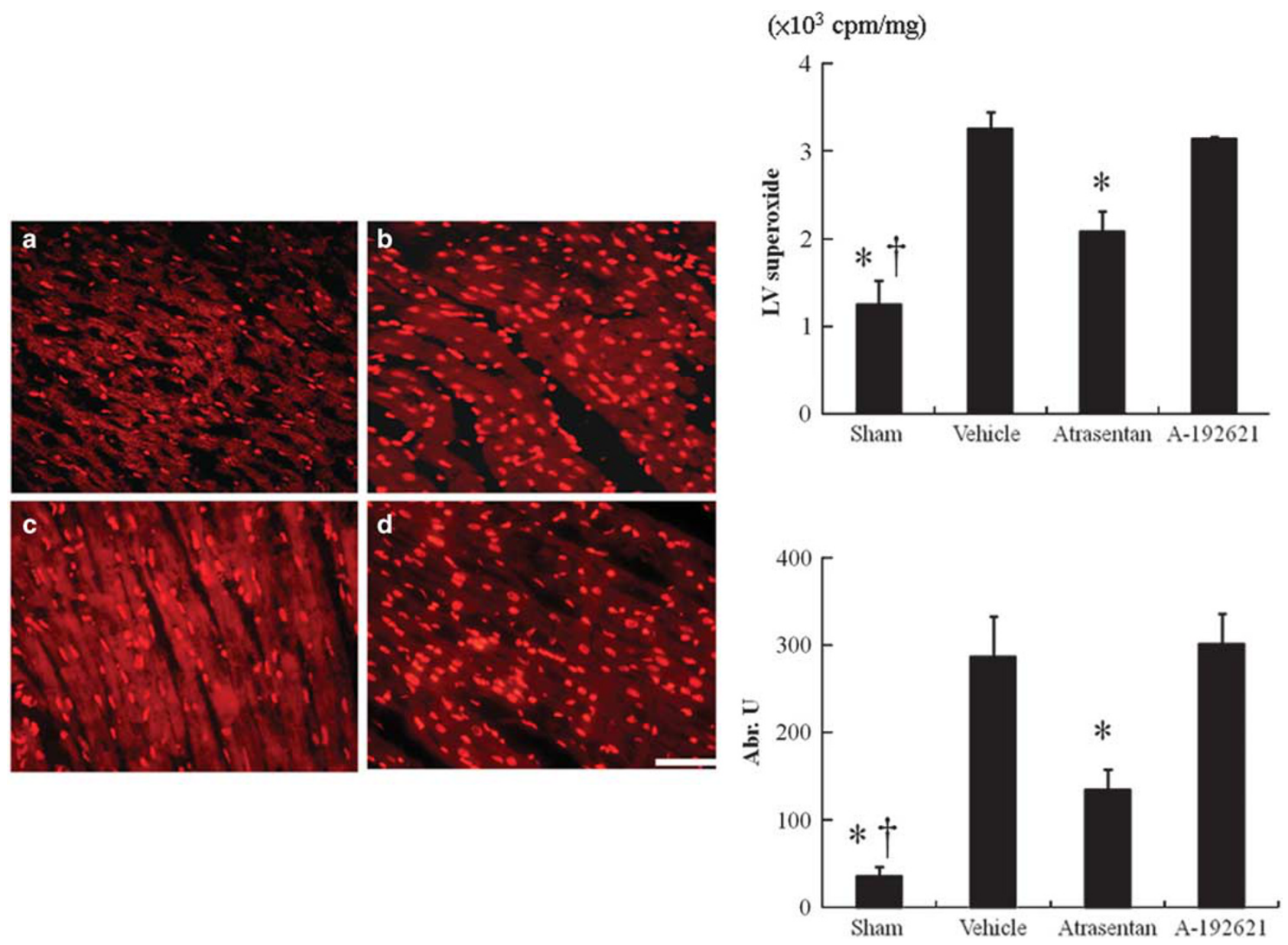

Figure 1 Myocardial superoxide measurement by chemiluminescence (upper panel) and dihydroethidium (DHE) staining (lower panel) from the remote zone. Compared with sham, the DHE fluorescence intensity in the myocardium of the vehicle-treated infarcted group was significantly increased. DHE staining (\%) in the remote zone. (a), sham ( $n=10)$; (b), infarction treated with vehicle $(n=11)$; (c), infarction treated with atrasentan $(n=11)$; (d), infarction treated with A-192621 $(n=12)$. Bar $=50 \mu \mathrm{m}$. Each column and bar represents mean \pm s.e. ${ }^{*} P<0.05$ compared with vehicle- and A-192621treated infarcted groups; ${ }^{\dagger} P<0.05$ compared with the atrasentan-treated infarcted rats.

with infarcted groups treated with either vehicle or A-192621. Infarct size did not differ among the infarcted groups.

\section{$\mathrm{ET}_{\mathrm{A}}$ Receptor Inhibition Attenuated Myocardial Norepinephrine Levels}

To investigate the cardiac sympathetic function, we determined the LV norepinephrine levels. LV norepinephrine levels were significantly upregulated 2.06-fold in the remote zone in the vehicle-treated rats than in sham-operated rats $(2.37 \pm 0.12 v s 1.15 \pm 0.05 \mu \mathrm{g} / \mathrm{g}$ protein, $P<0.0001$, Table 1$)$. Compared with vehicle or A-192621-treated rats, LV norepinephrine levels were significantly lower in the remote regions in the atrasentan-treated rats.

\section{Myocardial Superoxide Levels}

Superoxide production was significantly increased in remote LV tissues after MI (Figure 1, upper panel). Compared with vehicle-treated infarcted rats, myocardial superoxide levels were significantly decreased in atrasentan-treated rats.
However, when compared with atrasentan-treated infarcted rats, A-192621-treated infarcted rats had significantly higher myocardial superoxide levels.

DHE reacts with superoxide radicals to form ethidium bromide, which in turn intercalates with DNA to provide nuclear fluorescence as a marker of superoxide radical generation. As shown in Figure 1 lower panel, postinfarction remodeling markedly enhanced the intensity of the DHE staining in cardiomyocytes in the remote zone compared with those in the sham. However, the intensity of the fluorescent signal in the atrasentan group was significantly reduced relative to the vehicle and A-192621 groups.

\section{$\mathrm{ET}_{\mathrm{A}}$ Receptor Inhibition Attenuated Sympathetic Innervation}

The tyrosine hydroxylase-immunostained nerve fibers appeared to be oriented in the longitudinal axis of adjacent myofibers. The tyrosine hydroxylase-positive nerve area 
fraction was significantly larger in vehicle-treated infarcted rats than that in the sham group (Figure 2, upper). Infarcted rats in the atrasentan-treated group showed smaller nerve area fractions in the remote regions than rats in the vehicle- or A-192621-treated infarcted groups $(0.18 \pm 0.07$ vs $0.30 \pm 0.05$ and $0.27 \pm 0.03 \%$ in the A-192621 group, $P<0.001$, respectively). Similar to tyrosine hydroxylase results, GAP43positive (Figure 2, lower) and neurofilament-positive (data not shown) nerve area fractions were significantly attenuated in the atrasentan-treated infarcted rats compared with vehicle- or A-192621-treated infarcted rats.

\section{$\mathrm{ET}_{\mathrm{A}}$ Receptor Inhibition Attenuated NGF Protein and mRNA Expression}

Western blot shows that NGF levels are significantly upregulated 3.1-fold in the remote zone in the vehicletreated infarcted rats than in sham-operated rats $(P<0.0001$, Figure 3). Compared with vehicle- or A-192621-treated infarcted rats in atrasentan-treated rats, NGF levels were significantly lower in the remote zone.

PCR amplification of the cDNA revealed that the NGF mRNA expression showed a 2.7 -fold upregulation in the remote zone in the vehicle compared with the sham-operated rats $(P<0.0001$, Figure 4 , upper panel). In atrasentan-treated infarcted rats, the NGF mRNA expression was significantly decreased than those in the vehicle or A-192621.

\section{$\mathrm{ET}_{\mathrm{A}}$ Receptor Inhibition Attenuated Ventricular Arrhythmias}

To further elucidate the physiological effect of attenuated sympathetic reinnervation, ventricular pacing was performed. Arrhythmia score in sham-operated rats was very low $(0.1 \pm 0.1$, Figure 4, lower panel). In contrast, ventricular tachyarrhythmias consisting of ventricular tachycardia and ventricular fibrillation were inducible by programmed stimulation in vehicle-treated infarcted rats. Atrasentan treatment significantly decreased the inducibility of ventricular tachyarrhythmias compared with vehicle and A-192621 treatment.

\section{$\mathrm{ET}_{\mathrm{A}}$ Receptor Antagonist-Induced Attenuated NGF Levels by Attenuated Inhibition of PI3K/Akt/ GSK-3 $\beta /$ ROS Signaling \\ In vivo study}

To explore the possible downstream effectors of $\mathrm{ET}_{\mathrm{A}}$ receptor antagonist involved in the regulation of NGF levels, we assessed the effects of PI3K/Akt/GSK-3 $\beta$ signaling. As shown in Figure 3, MI significantly decreased the activation of PI3K and Akt, as shown by the p-PI3K-to-total-PI3K ratio and Akt2 (both $P<0.05$ ), suggesting that MI caused a significant impairment in PI3K and Akt signaling in the myocardium. Atrasentan treatment resulted in a significant increase $(P<0.01)$ in relative $\mathrm{p}$-PI3K level of $0.94 \pm 0.08$ compared with $0.58 \pm 0.07$ for relative level of $\mathrm{p}-\mathrm{PI} 3 \mathrm{~K}$ in vehicle treatment (Figure 3). Treatment with atrasentan enhanced the Akt2 by 1.9 -fold $(P<0.01)$ and GSK-3 $\beta$ phosphorylation by 1.8 -fold $(P<0.01)$ in the infarcted rats compared with the vehicle-treated rats, respectively.

\section{Ex vivo study}

To further confirm the role of PI3K/Akt in modulating NGF levels, we used PI3K inhibitors. This effect of atrasentan treatment on Akt2 activity, GSK-3 $\beta$ phosphorylation, and NGF levels was completely reversed by the inhibitors of PI3K signaling wortmannin and LY294002 (Figure 5). Finally, to confirm the role of GSK- $3 \beta$ in modulating NGF levels, we used LiCl, a GSK-3 $\beta$ inhibitor. Lithium administration significantly increased the intensity of GSK- $3 \beta$ phosphorylation and decreased the NGF levels compared with vehicle. Addition of lithium did not further attenuate NGF levels compared with atrasentan-treated rats alone.

To assess the axis of PI3K/GSK-3 $\beta$ in modulating free radical signaling, we measured myocardial peroxynitrite levels. As shown in Figure 5, atrasentan treatment significantly attenuated peroxynitrite levels compared with vehicle. However, peroxynitrite levels were reversed by the inhibitors of PI3K. The additional lithium administration did not provide further attenuation of peroxynitrite compared with atrasentan alone.

Finally, to further assess the role of atrasentan acting as antioxidants in modulating NGF levels, we determined the contribution of nitrosative stress to NGF levels, using the peroxynitrite generator SIN-1. As shown in Figure 6, the peroxynitrite generator blocked the attenuated effect of atrasentan on NGF levels.

\section{DISCUSSION}

Our present study shows for the first time that chronic treatment for 4 weeks with an $\mathrm{ET}_{\mathrm{A}}$ receptor antagonist leads to attenuated sympathetic innervation through PI3K/Akt/ GSK-3 $\beta /$ ROS pathway after MI. These results were concordant with beneficial effects of $\mathrm{ET}_{\mathrm{A}}$ receptor antagonists, as documented structurally by reduction in cardiac nerve sprouting and DHE staining, molecularly by myocardial NGF expression on mRNA and protein levels, biochemically by tissue superoxide, peroxynitrite and norepinephrine levels, and electrophysiologically by improvement of fatal ventricular tachyarrhythmias. These in vivo and ex vivo results indicate that depressed PI3K/Akt/GSK-3 $\beta /$ ROS-mediated NGF signaling is a critical mechanism, which is responsible for MI-associated sympathetic hyperinnervation during ventricular remodeling, and that $\mathrm{ET}_{\mathrm{A}}$ receptor antagonist-mediated restoration of PI3K/Akt contributes to attenuated NGF levels through inactivation of GSK-3 $\beta$. These findings highlight myocardial PI3K/Akt/GSK-3 $\beta$ as a cellular mechanism that underlies the remodeling of the sympathetic nervous system in post-infarcted rats. Indeed, our results were consistent with the findings of Goraca et al, ${ }^{31}$ showing that ET-1 increased ROS production through activating $\mathrm{ET}_{\mathrm{A}}$ receptor. ET-1 may increase superoxide anion by activating NADPH oxidase, ${ }^{32}$ 

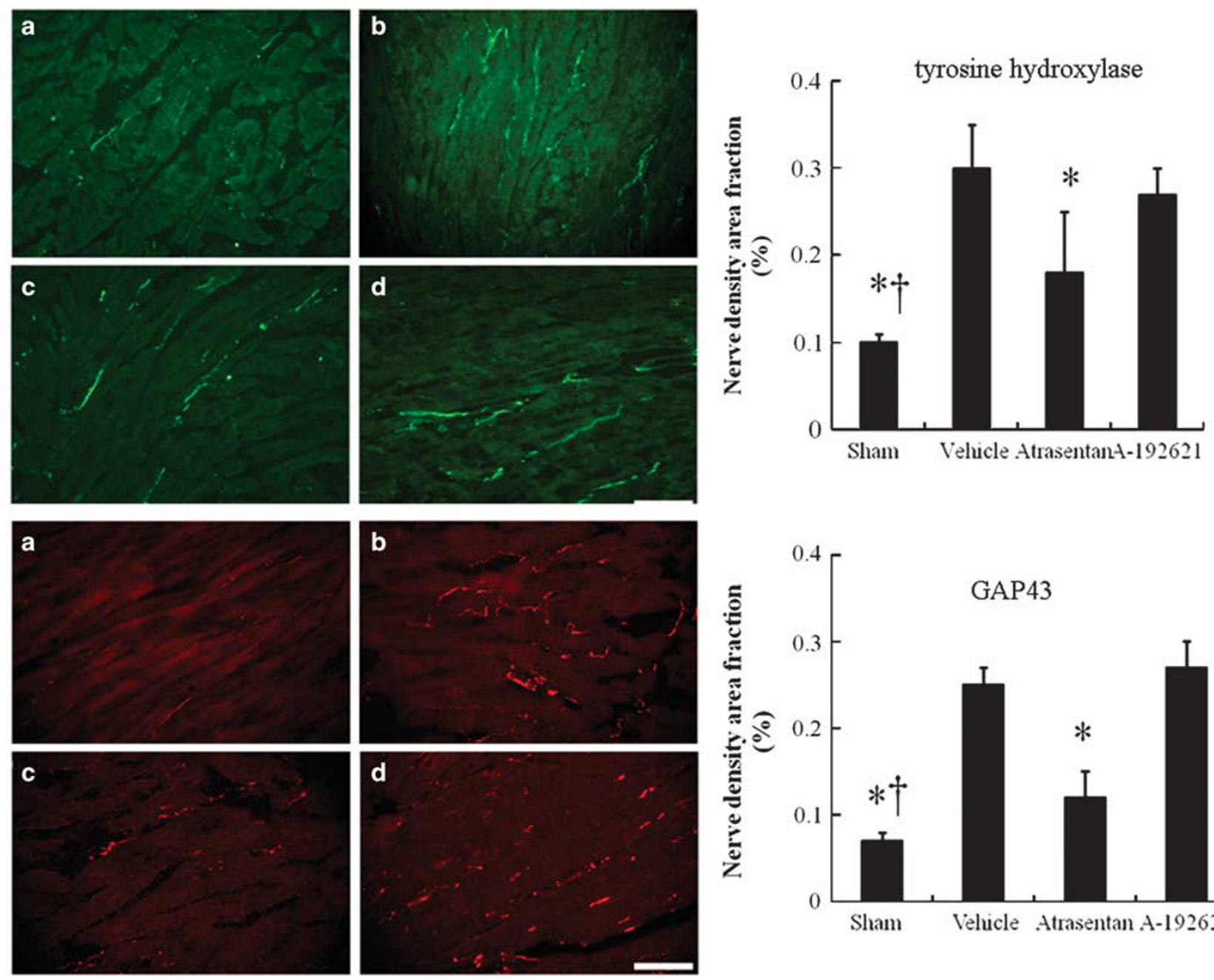

Figure 2 Immunofluorescent staining for tyrosine hydroxylase and growth-associated protein 43 (GAP43) from the remote regions (magnification $\times 400$ ). Upper, tyrosine hydroxylase. Tyrosine hydroxylase-positive nerve fibers are located between myofibrils and are oriented in longitudinal direction as that of the myofibrils. Lower, GAP43. (a), sham $(n=10)$; (b), infarction treated with vehicle $(n=11)$; (c), infarction treated with atrasentan $(n=11)$; (d), infarction treated with A-192621 $(n=12)$. Bar $=50 \mu \mathrm{m}$. Each column and bar represents mean \pm s.e. ${ }^{*} P<0.05$ compared with vehicle- and A-192621treated infarcted groups; $\uparrow P<0.05$ compared with the atrasentan-treated infarcted rats.

mitogen-activated protein kinase (MAPK), ${ }^{33}$ protein kinase $\mathrm{C},{ }^{34}$ nuclear factor- $\kappa \mathrm{B}$ pathway, ${ }^{35}$ or c-Jun-terminal kinase. ${ }^{36}$ This study showed that PI3K/Akt/GSK-3 $\beta$ axis is a novel molecular signaling pathway by which activation of $\mathrm{ET}_{\mathrm{A}}$ receptor enhanced ROS production.

Our results have linked the inactivation of PI3K/Akt/ GSK-3 $\beta /$ ROS via ET-1 binding to the $\mathrm{ET}_{\mathrm{A}}$ receptor as being essential for sympathetic innervation after infarction. The beneficial effect of $\mathrm{ET}_{\mathrm{A}}$ receptor antagonists on sympathetic reinnervation was supported by three lines of evidence (Figure 7):

1) The current results confirmed our previous study that the endogenous ET-1 level was significantly increased after infarction. ${ }^{1}$ This study demonstrates that infarction leads to an increase of myocardial NGF mRNA expression and protein levels. The chronic blockade of selective $\mathrm{ET}_{\mathrm{A}}$ receptors, not $\mathrm{ET}_{\mathrm{B}}$ receptor blockade, attenuated sympathetic reinnervation in the remote zone.

2) We showed that post-MI decreased the activation of the serine/threonine protein kinase, Akt, and its upstream mediator, PI3K, consistent with the previous results. ${ }^{37}$ This study showed that inhibition of the PI3K with wortmannin and LY294002 enhanced NGF levels and lithium (GSK-3 $\beta$ inhibitor) attenuated the increase of NGF levels, implying that the infarction-induced NGF increase depended on the PI3K/ Akt/GSK-3 $\beta$ pathway. Furthermore, addition of lithium did not further attenuate NGF levels in atrasentan-treated rats, implying a common pathway of $\mathrm{ET}_{\mathrm{A}}$ receptors and GSK-3 $\beta$ in NGF regulation. Atrasentan compensated for the impairment of PI3K activity by inactivating ET-1. 

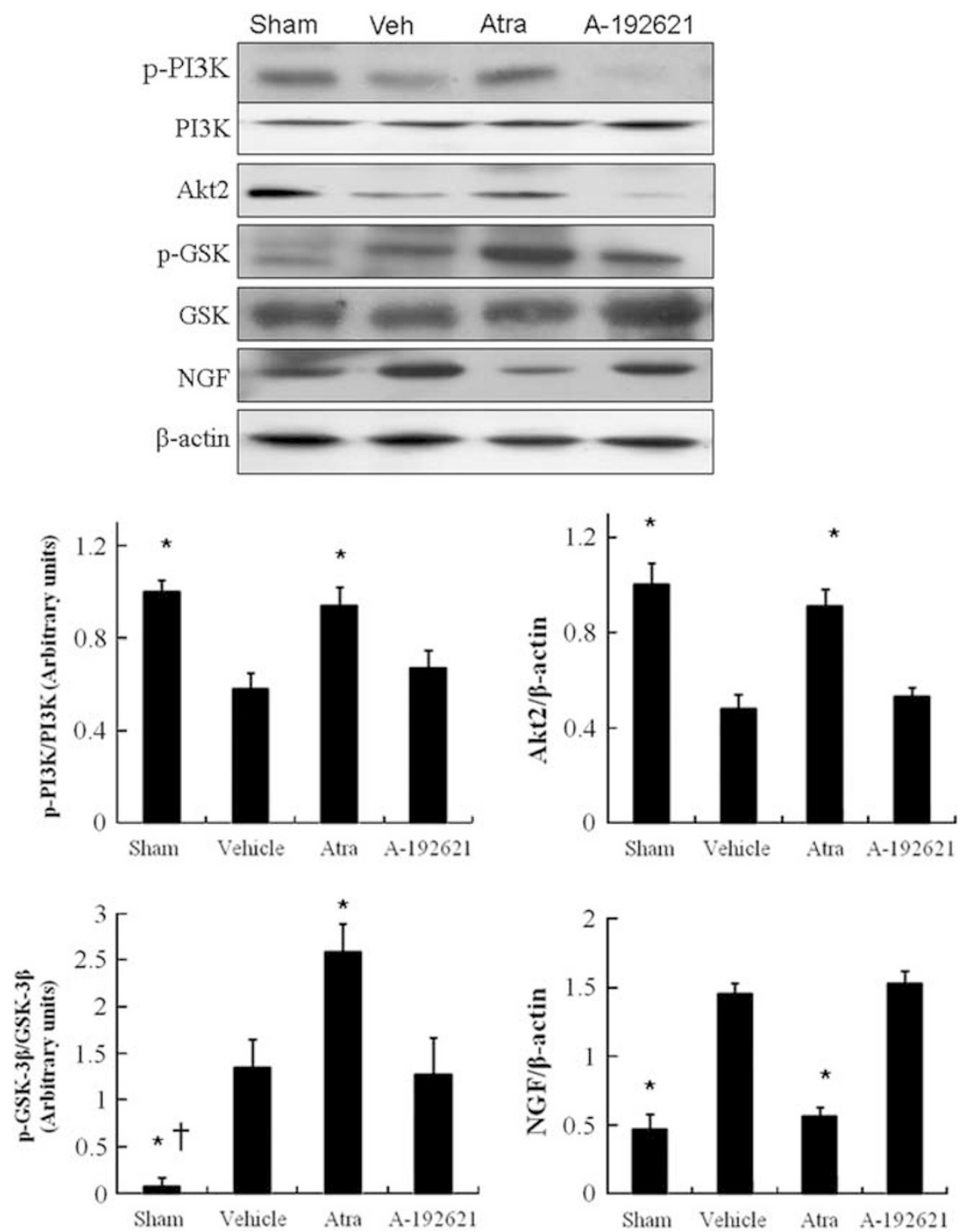

Figure 3 Western blot in homogenates of the left ventricular (LV) from the remote zone in an in vivo study. MI influenced the levels of phosphatidylinositol 3-kinase (PI3K), Akt2, glycogen synthase kinase (GSK-3ß), and nerve growth factor (NGF) (MW: 13 kDa). There was a significant increase in the levels of p-PI3K, Akt2 and p-GSK-3 $\beta$ in the atrasentan-treated infarcted rats compared with the vehicle-treated infarcted rats. Compared with vehicle- and A-192621-treated infarcted rats, atrasentan-treated infarcted rats had significantly lower NGF levels by quantitative analysis. Bar graphs represent the quantitative analysis and differences in the levels of $\mathrm{p}-\mathrm{PI} 3 \mathrm{~K}$ and $\mathrm{p}-\mathrm{GSK}-3 \beta$, after they were normalized with corresponding total proteins, respectively, in arbitrary units. Relative abundance was obtained by normalizing the density of Akt2 and NGF proteins against that of $\beta$-actin. Results are mean \pm s.e. of three independent experiments. sham $(n=10)$; vehicle $(n=11)$; atrasentan $(n=11)$; A-192621 $(n=12)$. ${ }^{*} P<0.05$ compared with vehicle- and A-192621-treated infarcted groups; ${ }^{\dagger} P<0.05$ compared with the atrasentan (Atra)-treated infarcted rats.

3) $\mathrm{ET}_{\mathrm{A}}$ receptor inhibitor attenuated the NGF levels through a PI3K/Akt/GSK-3 $\beta$-dependent superoxide pathway. Very recently, we have shown that activation of the PI3K/Akt/GSK-3 $\beta$ pathway efficiently protected hearts from ROS-induced injury after infarction. ${ }^{11}$ To identify whether the PI3K pathway has a role in antioxidation, we examined the effects of the PI3K inhibitors wortmannin and LY294002 on the infarcted hearts on myocardial ROS levels. We found that the PI3K inhibitors canceled the antioxidant effects of atrasentan (Figure 5).

Superoxide might be the mediator responsible for increased NGF levels. SIN-1 significantly increased the attenuated NGF levels in infarcted rat hearts treated with atrasentan. SIN-1 generates $\mathrm{ONOO}-$ by producing both $\mathrm{O} 2 \cdot \boldsymbol{-}$ and $\cdot \mathrm{NO}$. However, owing to its very short half-life at physiological $\mathrm{pH}$, endogenous formation of $\mathrm{ONOO}$ - cannot be directly detected in biological systems. Therefore, to estimate basal ONOO - formation, we measured the most widely accepted marker of ONOO-, free nitrotyrosine. Peroxynitrite has been shown to activate activator protein- 1 activation, ${ }^{14}$ which in turn to activate the NGF promoter and enhance the transcripts of NGF. These results extended our previous findings that antioxidation by administering $\mathrm{N}$-acetylcysteine 

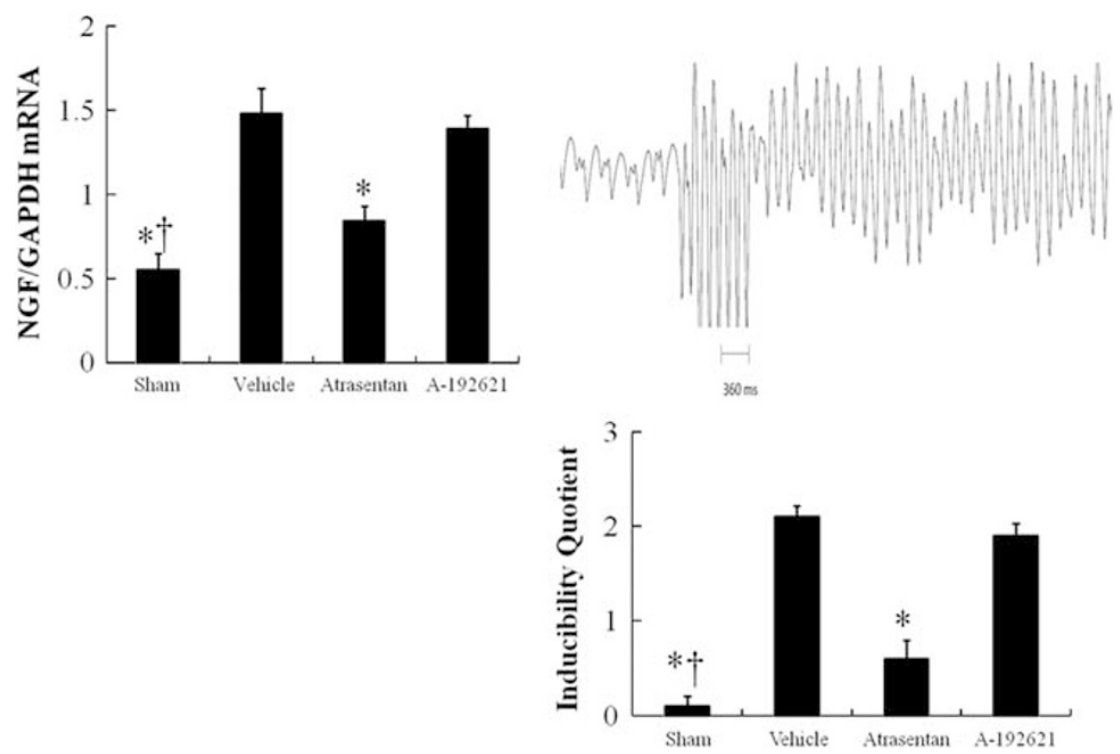

Figure 4 Left ventricular (LV) nerve growth factor (NGF) mRNA expression and inducibility quotient of ventricular arrhythmias by programmed electrical stimulation 4 weeks after myocardial infarction (MI). A representative sustained ventricular arrhythmia induced by ventricular pacing in an infarcted rat treated with vehicle. After eight basic stimuli at a cycle length of $120 \mathrm{~ms}$, sustained ventricular tachyarrhythmias were observed (score: 7). Each column and bar represents mean \pm s.e. sham $(n=10)$; vehicle $(n=11)$; atrasentan $(n=11)$; A-192621 $(n=12) .{ }^{*} P<0.05$ compared with vehicle- and A-192621treated infarcted groups; ${ }^{\dagger} P<0.05$ compared with the atrasentan-treated infarcted rats.

or xanthine oxidase inhibitors attenuated sympathetic hyperinnervation after infarction. ${ }^{30,38}$

\section{Other Mechanisms}

The present study suggests that the mechanisms of ET receptor antagonist-induced neuroprotection and antiarrhythmia are related to attenuated NGF expression through a PI3K/Akt/GSK-3 $\beta /$ ROS axis. However, the PI3K/Akt/GSK$-3 \beta$ axis has been shown to have multifaceted effects on heart and other potential mechanisms need to be studied such as direct electrical remodeling and nerve microtubule modulation. PI3K/Akt might prevent fatal arrhythmias by directly inhibiting electrophysiological alterations. ${ }^{39}$ Electrophysiological studies established a role of PI3K/Akt in the regulation of membrane ion transport systems that determine membrane repolarization. ${ }^{39}$ Ionic channels are important for the induction of abnormal automaticity and reentrant arrhythmias. Besides, it is generally accepted that PI3K has a central role in cell signaling in neurite extension. ${ }^{40}$ GSK-3 activity may have a role in nerve integrity. A certain level of GSK-3 activity is essential for a neurite to extend as an axon, and consequently the formation of the axon initial segment. ${ }^{41}$ Cytoplasmic linker protein-associated protein 2 restricts axon growth when bound along microtubule lattices upon GSK-3 inhibition. ${ }^{41}$ When GSK-3 activity is greatly suppressed, cytoplasmic linker protein-associated protein 2 mediates axon growth inhibition in adult dorsal root ganglion neurons. Thus, the PI3K/Akt/GSK-3 $\beta$ axis may be associated with attenuated nerve regeneration by a mechanism not involved in NGF. Second, ET-1 via the $\mathrm{ET}_{\mathrm{A}}$ receptor forms a molecular complex with the Src family tyrosine kinase c-Yes. ${ }^{42}$ The $\mathrm{ET}_{\mathrm{A}}$ receptor-tyrosine kinase complexes contribute to regulation of two distinct intracellular signaling pathways: the MAPK pathway and the PI3K pathway. ${ }^{42}$ The possibility of cross-talk between these two pathways is still not completely elucidated. The degree of activation differs, and the diverse level of activation of MAPK pathway and PI3K pathway may explain the different effects of tissues; however, little is known about how various ligands exhibit distinctive effects. We cannot exclude the possibility that MAPK is an alternative transduction pathway in this neuritogenesis. However, given the PI3K inhibitors, wortmannin and LY294002, completely reversed the attenuated atrasentan-induced NGF levels (Figure 5), it is reasonable to suppose that the MAPK pathway may have a minor role in atrasentan-attenuated nerve regeneration. Finally, although some of the effects of ET-1 are associated with an increase in intracellular calcium concentration, the pathophysiological responses elicited by ET-1 can be both calcium-dependent and calcium-independent. ${ }^{43,44}$ If the beneficial effect of $\mathrm{ET}_{\mathrm{A}}$ antagonist on attenuated NGF levels and subsequent attenuated fatal arrhythmias was explained by decreased intracellular calcium rise, the rats treated with wortmannin, a PI3K inhibitor without affecting intracellular calcium concentrations, ${ }^{45}$ should be expected to have similar NGF levels compared with atrasentan alone. Obviously, this was not the case (Figure 5). After adding either wortmannin or LY294002, the NGF levels were significantly increased compared with atrasentan alone, implying PI3K signaling pathway has a role in modulating NGF levels. However, we cannot exclude the possibility of $\mathrm{ET}_{\mathrm{A}}$ receptor inhibition in 

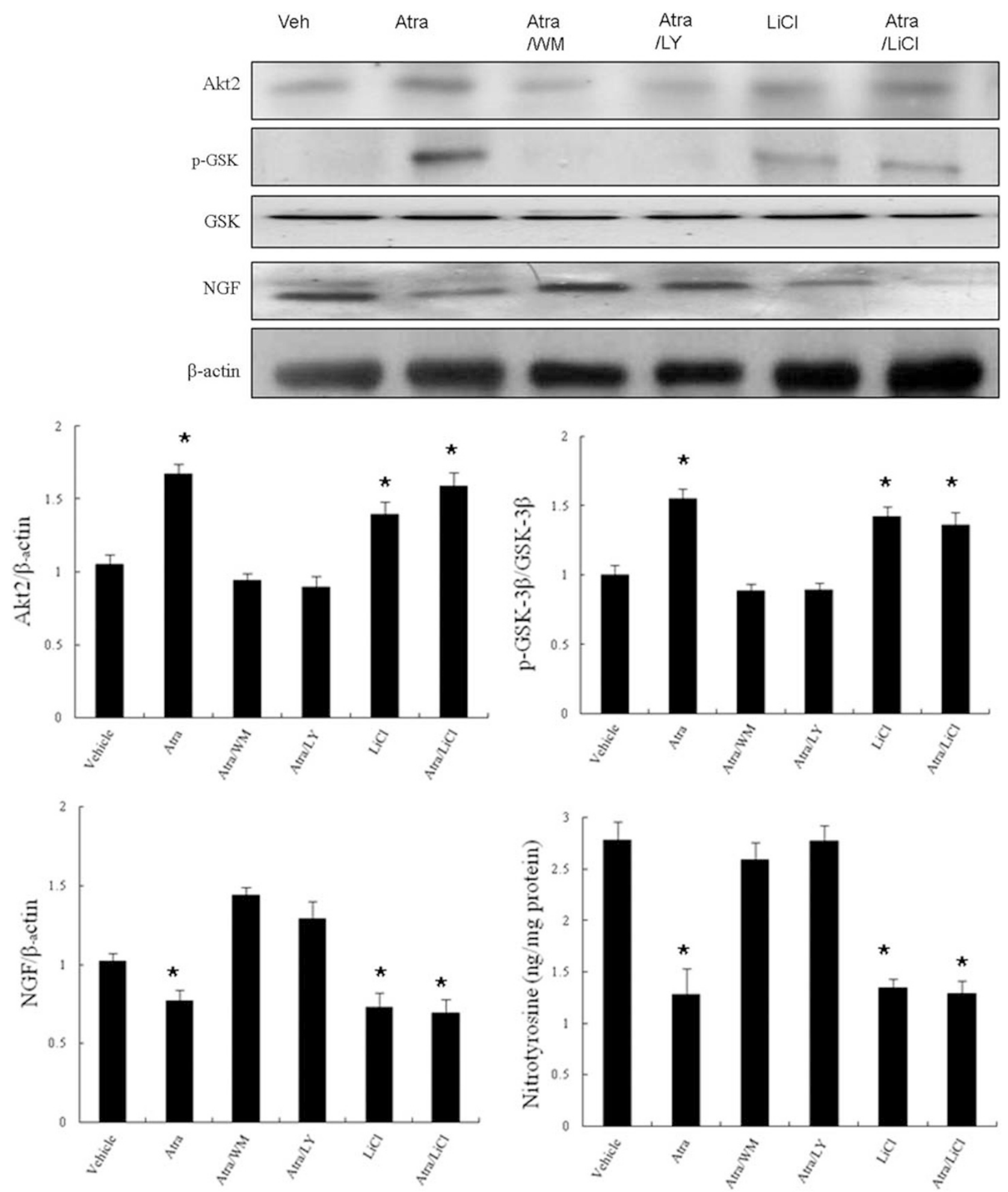

Figure 5 Experiment 2 (ex vivo). Western blot in homogenates of the left ventricular (LV) and myocardial nitrotyrosine from the remote zone in an ex vivo study. In a rat isolated heart model, the attenuated nerve growth factor (NGF) protein levels in response to atrasentan are inhibited by the PI3K/ Akt inhibitors, wortmannin (WM) and LY294002 (LY), and the glycogen synthase kinase (GSK-3 $\beta$ ) inhibitor, lithium chloride (LiCl). Relative abundance was obtained by normalizing the density of Akt2 and NGF proteins against that of $\beta$-actin. Results are mean \pm s.e. of three independent experiments. $n=5$ in each group. ${ }^{*} P<0.05$ compared with vehicle-, atrasentan (Atra)+wortmannin-, and atrasentan (Atra)+LY294002-treated infarcted rats. 

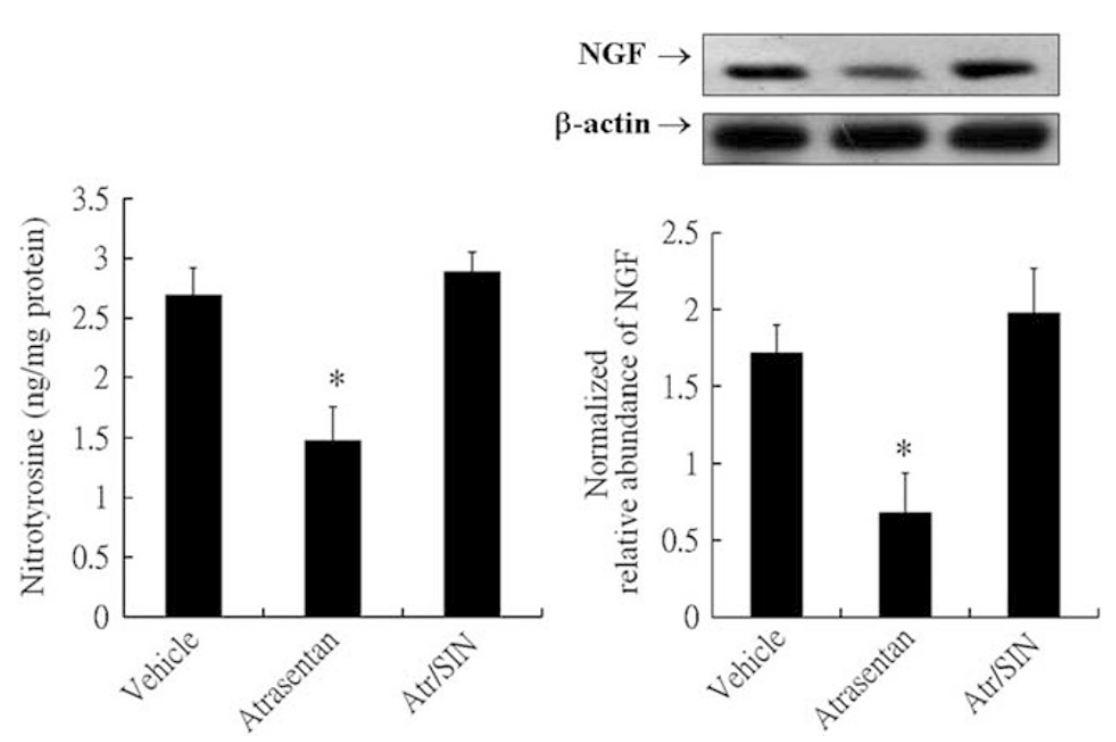

Figure 6 Experiment 3 (ex vivo). Effect of SIN-1 on atrasentan-induced myocardial nitrotyrosine and nerve growth factor (NGF) levels in an isolated heart study. The atrasentan-treated hearts had significantly decreased nitrotyrosine and NGF levels compared with vehicle. However, the nitrotyrosine and NGF levels cannot be attenuated after addition of SIN-1 compared with atrasentan alone. $n=5$ in each group. ${ }^{*} P<0.05$ compared with vehicle- and atrasentan (Atr)/SIN-1-treated groups.

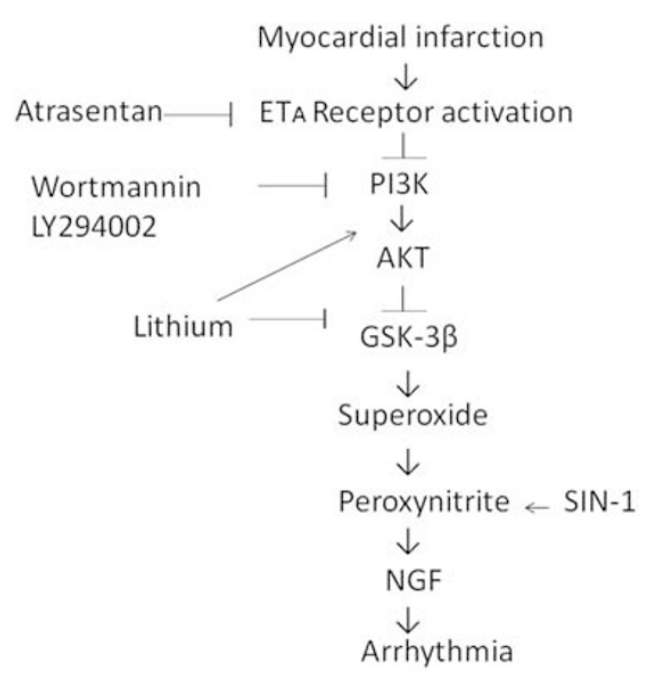

Figure 7 Reaction sequences leading to attenuated arrhythmias. The diagram summarizes the immunofluorescent, molecular, and pharmacological evidence presented in this report. Inhibition of these signaling pathways by their respective inhibitors is indicated by the vertical lines.

intracellular calcium as a cause of attenuated fatal arrhythmias. Regardless of the relative importance of each of these factors, all of the ET receptor antagonist-caused changes are compatible with our understanding of their protective effects against ventricular arrhythmias.

\section{Clinical Implications}

Of patients who develop acute MI, 15-20\% have a history of previous infarction, which is a predictor of high post-discharge mortality rate at 1 year. ${ }^{46}$ Thus, improvement in antiarrhythmic signaling during post-infarct remodeling is not a negligible problem in the clinical areas. Given that ET-1 is strongly induced during post-infarcted remodeling, the beneficial effects of $\mathrm{ET}_{\mathrm{A}}$ receptor antagonists as antiarrhythmic agents may be related to the remodeling of the sympathetic nervous system that is mediated by the $\mathrm{PI} 3 \mathrm{~K} / \mathrm{Akt} / \mathrm{GSK}-3 \beta$ pathway. We provide in vivo evidence for a role of $\mathrm{ET}_{\mathrm{A}}$ receptor antagonists during nerve regeneration in the mature nervous system after infarction that enables regulation of gene expression in myocardium of live animals. Therefore, the interventions that activate the PI3K/Akt/ GSK- $3 \beta$ signaling pathway may have therapeutic benefits for post-MI-associated complications. Besides, administration of $\mathrm{ET}_{\mathrm{A}}$ receptor antagonists showed improvement of ventricular remodeling assessed by $+\mathrm{dP} / \mathrm{d} t,-\mathrm{dP} / \mathrm{d} t$, right ventricular weight/body weight ratio, and lung weight/ body weight ratio in this study. Ventricular remodeling after MI is the major cause of heart failure due to LV systolic dysfunction. Effective anti-remodeling treatment should be initiated as soon as possible and monitored after MI management strategy.

\section{Study Limitations}

There are some limitations in the present study that have to be acknowledged. First, our finding in rats cannot necessarily be extrapolated to humans with MI. Different species have been shown to have different distribution of ET receptor population. The contribution of $\mathrm{ET}_{\mathrm{A}}$ receptors has been shown to assume a less significance in humans because they account for up to $60 \%$ of the total ET receptors in ventricular myocardium compared with $85 \%$ in rat ventricular myocardium. ${ }^{47}$ Second, the analysis could only be performed 
on tissues from surviving animals. This can thus bias the results toward a probably less severe situation, as only animals that coped well with post-infarction remodeling were investigated. Third, our studies on PI3K/Akt signaling were obtained by pharmacological inhibition. Thus, we cannot exclude the non-specific actions of drugs. For these reasons we chose to study two structurally unrelated inhibitors in order to increase the veracity of our conclusions. Finally, given the ET receptors were detected in myocardial sympathetic nerve varicosities ${ }^{3}$ and cardiomyocytes, ${ }^{8}$ the ET released after MI could act as an autocrine or paracrine factor that modulates the activity of the sympathetic nerves themselves or of cardiomyocytes adjacent to the sympathetic nerves. Myocardiums from the remote zone, either in in vivo or ex vivo experiments, contain variable amounts of intrinsic myocardial nerves and cardiomyocytes. Thus, our study did not allow the determination of the underlying critical cell types to participate in ET-1-mediated NGF secretion in the cardiac tissue.

\section{CONCLUSIONS}

These data show that MI causes sympathetic hyperinnervation, possibly by increased ET-1 and attenuating the PI3K/ Akt/GSK-3 $\beta /$ ROS signaling cascade. $\mathrm{ET}_{\mathrm{A}}$ blockade attenuates sympathetic hyperinnervation by activating the PI3K/Akt/ GSK-3 $\beta /$ ROS signaling cascade. Collectively, our finding should shed some light on our understanding of post-MIassociated arrhythmias and its reversal by $\mathrm{ET}_{\mathrm{A}}$ blocker and may help to identify a new therapeutic regimen for post-MIassociated cardiovascular diseases.

\section{ACKNOWLEDGMENTS}

This work was supported by the grants of An Nan Hospital (ANHRF105-01), China Medical University (CMU105-S-43), and Ministry of Science and Technology (MOST 105-2314-B-039-042), Taiwan.

These authors take responsibility for all aspects of the reliability and freedom from bias of the data presented and their discussed interpretation.

\section{DISCLOSURE/CONFLICT OF INTEREST}

The authors declare no conflict of interest.

1. Lee TM, Chen CC, Lin MS, et al. Effect of endothelin receptor antagonists on ventricular susceptibility in postinfarcted rats. Am J Physiol Heart Circ Physiol 2008;294:H1871-H1879.

2. Rich S, McLaughlin VV. Endothelin receptor blockers in cardiovascular disease. Circulation 2003;108:2184-2190.

3. Isaka M, Kudo A, Imamura $M$, et al. Endothelin receptors, localized in sympathetic nerve terminals of the heart, modulate norepinephrine release and reperfusion arrhythmias. Basic Res Cardiol 2007;102: $154-162$.

4. Matsumoto $\mathrm{Y}$, Aihara $\mathrm{H}$, Yamauchi-Kohno $\mathrm{R}$, et al. Long-term endothelin $A$ receptor blockade inhibits electrical remodeling in cardiomyopathic hamsters. Circulation 2002;106:613-619.

5. Cao JM, Chen LS, KenKnight BH, et al. Nerve spouting and sudden cardiac death. Circ Res 2000;96:816-821.

6. Lai AC, Wallner K, Cao JM, et al. Colocalization of tenascin and sympathetic nerves in a canine model of nerve spouting and sudden cardiac death. J Cardiovasc Electrophysiol 2000;11:1345-1351.

7. Brauer MM, Chavez-Genaro R, Llodra J, et al. Effects of chronic oestrogen treatment are not selectively for uterine noradrenaline- containing sympathetic nerves: a transplantation study. J Anat 2000;196:347-355.

8. leda M, Fukuda K, Hisaka $Y$, et al. Endothelin-1 regulates cardiac sympathetic innervation in the rodent heart by controlling nerve growth factor expression. J Clin Invest 2004;113:876-884.

9. Higuchi M, Onishi K, Masuyama N, et al. The phosphatidylinositol-3 kinase (PI3K)-Akt pathway suppresses neurite branch formation in NGF-treated PC12 cells. Genes Cells 2003;8:657-669.

10. Jiang $\mathrm{H}$, Guo W, Liang $\mathrm{X}$, et al. Both the establishment and the maintenance of neuronal polarity require active mechanisms: critical roles of GSK-3beta and its upstream regulators. Cell 2005;120: $123-135$.

11. Lee TM, Lin SZ, Chang NC. Antiarrhythmic effect of lithium in rats after myocardial infarction by activation of $\mathrm{Nrf2} / \mathrm{HO}-1$ signaling. Free Radic Biol Med 2014;77:71-81.

12. Colangelo AM, Johnson PF, Mocchetti I. Beta-adrenergic receptorinduced activation of nerve growth factor gene transcription in rat cerebral cortex involves CCAAT/enhancer-binding protein delta. Proc Natl Acad Sci USA 1998:95:10920-10925.

13. Abate C, Patel L, Rauscher 3rd FJ, et al. Redox regulation of fos and jun DNA-binding activity in vitro. Science 1990;249:1157-1161.

14. Vargas $M R$, Pehar $M$, Cassina $P$, et al. Stimulation of nerve growth factor expression in astrocytes by peroxynitrite. In Vivo 2004;18: 269-274.

15. Lee TM, Chou TF, Tsai CH. Effects of pravastatin on cardiomyocyte hypertrophy and ventricular vulnerability in normolipidemic rats after myocardial infarction. J Mol Cell Cardiol 2003;35:1449-1459.

16. Pollock DM, Pollock JS. Evidence for endothelin involvement in the response to high salt. Am J Physiol 2001;281:F144-F150.

17. Xia $\mathrm{QG}$, Chung $\mathrm{O}$, Spitznagel $\mathrm{H}$, et al. Significance of timing of angiotensin AT1 receptor blockade in rats with myocardial infarctioninduced heart failure. Cardiovasc Res 2001:49:110-117.

18. Bélichard P, Savard P, Cardinal R et al. Markedly different effects on ventricular remodeling result in a decrease in inducibility of ventricular arrhythmias. J Am Coll Cardiol 1994;23:505-513.

19. Fukumoto $\mathrm{T}$, Tawa M, Kitada $\mathrm{K}$ et al. Different effects of AT1 receptor antagonist and ETA receptor antagonist on ischemia-induced norepinephrine release in rat hearts. J Cardiovasc Pharmacol 2012;60: $55-60$.

20. Miki T, Miura T, Yano T, et al. Alteration in erythropoietin-induced cardioprotective signaling by postinfarct ventricular remodeling. J Pharmacol Exp Ther 2006;317:68-75.

21. Nemoto T, Kanai T, Yanagita $T$, et al. Regulation of Akt mRNA and protein levels by glycogen synthase kinase-3beta in adrenal chromaffin cells: effects of $\mathrm{LiCl}$ and SB216763. Eur J Pharmacol 2008:586:82-89.

22. Dutka TL, Mollica JP, Lamb GD. Differential effects of peroxynitrite on contractile protein properties in fast- and slow-twitch skeletal muscle fibers of rat. J Appl Physiol 2011;110:705-706.

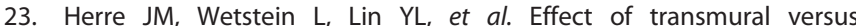
nontransmural myocardial infarction on inducibility of ventricular arrhythmias during sympathetic stimulation in dogs. J Am Coll Cardiol 1988;11:414-421.

24. Kang CS, Chen CC, Lin CC, et al. Effect of ATP-sensitive potassium channel agonists on sympathetic hyperinnervation in postinfarcted rat hearts. Am J Physiol Heart Circ Physiol 2009;296: H1949-H1959.

25. Diez H, Garrido JJ, Wandosell F. Specific roles of Akt isoforms in apoptosis and axon growth regulation in neurons. PLoS One 2012;7: e32715.

26. Santi SA, Lee $\mathrm{H}$. The Akt isoforms are present at distinct subcellular locations. Am J Physiol Cell Physiol 2010;298:C580-C591.

27. Cuevas BD, Lu Y, Mao M, et al. Tyrosine phosphorylation of $\mathrm{p} 85$ relieves its inhibitory activity on phosphatidylinositol 3-kinase. J Biol Chem 2001;276:27455-27461.

28. Meiri KF, Pfenninger KH, Willard MB. Growth-associated protein, GAP-43, a polypeptide that is induced when neurons extend axons, is a component of growth cones and corresponds to pp46, a major polypeptide of a subcellular fraction enriched in growth cones. Proc Natl Acad Sci USA 1986:83:3537-3541.

29. Dahlstrom A. Observations on the accumulation of noradrenaline in the proximal and distal parts of peripheral adrenergic nerves after compression. J Anat 1965;99:677-689. 
30. Lee TM, Lin MS, Chou TF, et al. Adjunctive $17 \beta$-estradiol administration reduces infarct size by altered expression of canine myocardial connexin43 protein. Cardiovasc Res 2004;63:109-117.

31. Gorąca A, Kleniewska P, Skibska B. ET-1 mediates the release of reactive oxygen species and TNF-a in lung tissue by protein kinase $C a$ and $\beta 1$. Pharmacol Rep 2016;68:121-126.

32. Chakraborti S, Chowdhury A, Chakraborti T. Cross-talk between ( $p 38$ ) MAPK and ia in regulating CPLA2 activity by ET-1 in pulmonary smooth muscle cells. Mol Cell Biochem 2015;400:107-123.

33. Romero $M$, Jimenez $R$, Sanchez $M$, et al. Vascular superoxide production by endothelin-1 requires Src non-receptor protein tyrosine kinase and MAPK activation. Atherosclerosis 2010;212:78-85.

34. Chatterjee $\mathrm{S}$, Browning EA, Hong N, et al. Membrane depolarization is the trigger for PI3K/Akt activation and leads to the generation of ROS Am J Physiol Heart Circ Physiol 2012;302:H105-H114.

35. Kleniewska P, Piechota-Polanczyk A, Michalski $L$ et al. Influence of block of NF-kappa B signaling pathway on oxidative stress in the liver homogenates. Oxid Med Cell Longev 2013;2013:308358.

36. Nishida M, Onohara N, Sato $Y$, et al. Galpha12/13- mediated upregulation of TRPC 6 negatively regulates endothelin-1-induced cardiac myofibroblast formation and collagen synthesis through nuclear factor of activated T cells activation. J Biol Chem 2007;282:23117-23128.

37. Wang $Y$, Wang $S$, Wier WG, et al. Exercise improves the dilatation function of mesenteric arteries in postmyocardial infarction rats via a PI3K/Akt/eNOS pathway-mediated mechanism. Am J Physiol Heart Circ Physiol 2010;299:H2097-H2106.

38. Lee TM, Chen CC, Hsu YJ. Differential effects of NADPH oxidase and xanthine oxidase inhibition on sympathetic reinnervation in postinfarct rat hearts. Free Radic Biol Med 2011;50:1461-1470.
39. Macrez N, Mironneau C, Carricaburu V, et al. Phosphoinositide 3-kinase isoforms selectively couple receptors to vascular L-type Ca2+ channels. Circ Res 2001;89:692-699.

40. Kimura K, Hattori S, Kabuyama Y, et al. Neurite outgrowth of PC12 cells is suppressed by wortmannin, a specific inhibitor of phosphatidylinositol 3-kinase. J Biol Chem 1994;269:18961-18967.

41. Hur EM, Saijilafu, Lee BD, et al. GSK3 controls axon growth via CLASPmediated regulation of growth cone microtubules. Genes Dev 2011;25: 1968-1981.

42. Imamura T, Huang J, Dalle $S$, et al. $\beta$-Arrestin-mediated recruitment of the Src family kinase Yes mediates endothelin-1-stimulated glucose transport. J Biol Chem 2001;276:43663-43667.

43. Dallas A, Khalil RA. Ca2+ antagonist insensitive coronary smooth muscle contraction involves activation of epsilon-protein kinase C-dependent pathway. Am J Physiol Cell Physiol 2003;285: C1454-C1463.

44. Itoh $\mathrm{H}$, Higuchi $\mathrm{H}$, Hiraoka $\mathrm{N}$, et al. Contraction of rat thoracic aorta strips by endothelin-1 in the absence of extracellular $\mathrm{Ca} 2+\mathrm{Br} J$ Pharmacol 1991;104:847-852.

45. Ethier MF, Madison JM. LY294002, but not wortmannin, increases intracellular calcium and inhibits calcium transients in bovine and human airway smooth muscle cells. Cell Calcium 2002;32:31-38.

46. Califf RM, Pieper KS, Lee KL, et al. Prediction of 1-year survival after thrombolysis for acute myocardial infarction in the global utilization of streptokinase and TPA for occluded coronary arteries trial. Circulation 2000;101:2231-2238.

47. Molenaar P, O'Reilly G, Sharkey A. Characteristics and localisation of endothelin receptor subtypes in the human AV conducting system and myocardium. Circ Res 1993;72:526-538. 